\title{
Types of Human Stem Cells and Their Therapeutic Applications
}

\author{
Sandro Eridani \\ Department of Biomedical Science and Technology, University of Milano, Milano, Italy \\ Email: seridani@gmail.com
}

Received 23 January 2014; revised 20 February 2014; accepted 27 February 2014

Copyright (C) 2014 by author and Scientific Research Publishing Inc.

This work is licensed under the Creative Commons Attribution International License (CC BY). http://creativecommons.org/licenses/by/4.0/

(c) (i) Open Access

\begin{abstract}
The present review examines in the first place various kinds of naturally occurring stem cells, including germ cells and embryonic stem cells (ES cells), as well as haemopoietic stem cells, which are historically the first to be used for medical treatment. Attention is also given to cancer stem cells, as a source of perseverant malignant disease. The main interest is now represented by the variety of somatic cells, which can be re-programmed to different types of differentiated cells, the so-called induced pluripotent stem cells (IPSC's). Focus is now directed not only to the factors which make such events possible like de-differentiation and reconversion but also to the stages involved in this process. It is actually postulated that the transition from differentiated cells to pluripotent cells follows a definite sequence with evidence of two waves of gene regulations. Main applications of stem cell therapy are reviewed, from the established use of haemopoietic stem cells for clinical transplantation in a variety of haematological disorders to the initial attempts to employ stem cells for the treatment of other disparate conditions. Problems related to stem cell treatment with both ES and IPS cells, like the necessity of a large in vitro expansion to provide sufficient amounts of cells and the related risk of genomic abnormalities are illustrated. The necessity of safe procedures for the development of this venture is also outlined.
\end{abstract}

\section{Keywords}

Stem Cells Classes, Embryonic and Germ Stem Cells, Somatic Cell Reprogramming, Induced Plueripotent Stem Cells, Epigenetic Factors, Regenerative Therapy

\section{Introduction}

The properties and applications of different types of stem cells have received an incredible degree of attention in recent years, which was difficult to imagine during the first attempts to move into this area. It has been therefore only natural that many studies have appeared with the aim to characterize various classes of cell progenitors, 
their versatility and clinical applications [1]-[4].

It has been indeed in the clinical field that stem cells have occupied a very important place, first in the haemato- and immunological pathology with good success but more recently, in other areas like neurological, cardiological and metabolic disorders, where trials are still in an early stage. It also has to be mentioned the use of stem cells as instruments of gene therapy, as they can be loaded with normal genes and transferred into tissues carrying genetic abnormalities [5].

\section{Historical Background}

The discovery of haemopoietic stem cells (as distinct from embryonic stem cells), capable of producing a variety of differentiated blood cells, can be traced to the immediate post-2nd world war, although earlier work had anticipated the possible existence of such elements. It was indeed in the late Forties that it was shown how mice could be protected from irradiation injury by shielding the spleen [6]. In another study it was demonstrated that protection from irradiation could be obtained by infusion of spleen or marrow cells [7]. Doubts were raised about the cellular or humoral nature of such protection, but they were solved when, after infusion of marrow cells and subsequent post-irradiation recovery, it was found that the newly formed marrow cells had cytological features of the marrow donor, thus pointing to the action of cellular factors [8].

Only a few years later a remarkable breakthrough was the demonstration of haemopoietic stem cells, obtained by experiments carried out to study the radiation sensitivity of mouse bone marrow cells [9]. The discovery was some how accidental, as the Authors pointed out. It was actually found the existence of repopulating cells, capable to form macroscopic colonies in the spleen of irradiated mice. Such cells were called "spleen colony-forming units (or CFU-S), a denomination based on the evidence, with the caveat to prove their ability of self-renewal before calling them truly stem cells. It was soon demonstrated that spleen colonies contained, in turn, a few colony-forming cells, thus satisfying the criteria of both differentiation and self-renewal capacity [10]. Following these results, it was soon debated if the stem cell decision of self-renewal v. differentiation could be an inherited property or the process would obey no particular rule and therefore should be considered as following an unpredictable, "stochastic" model, obviously difficult to demonstrate [11].

Studies on the heterogeneity of haemopoietic stem cells were focused on their variable capacity of self-renewal. The result was the isolation of two different classes, the long-term (LT-HSC) and the short term (STHSC) reconstitutive stem cells, the former capable of permanent self-renewal capacity, and the latter endowed only with a time-limited self-renewal capacity, about 8 weeks [12].

Another relevant area of investigation was the ontogeny of haemopoietic stem cells. It is actually postulated that early stem cells are totipotent progenitors, found in the inner cell mass of the blastocyst, which can originate both somatic progenitors and primitive germ-line stem cells. These cells, discovered in mouse embryo [13] are called embryonic stem cells (ES cells), capable to generate all somatic cells. They were obtained for the first time from human in blastocysts 1998 [14], raising a heated debate about the possibility to develop human tissues and organs from such material. However blastocysts are not the only source of pluripotent cells. ES-cells can be obtained by primordial germ cells (Eg-cells), which appear at a late embryonic stage of development [15]. Applications of such primitive precursors will be described. Haemopoietic progenitors are already found in the yolk sac blood islands [16], with successive migration to foetal liver, spleen and bone marrow [17]. They will form a prominent part of the present review as they represent the best studied cells in this field and have been successfully tested in clinical applications.

\section{Stem Cell Classes and Properties}

It is generally accepted that an essential property of stem cells is the self-renewal capacity during the entire life. In this respect, among germ line stem cells, only male spermatogonial cells were believed to possess this property and were thus called "true stem cells. It has been later claimed that adult mouse ovary contains germ cells capable to produce oocytes and follicles in the postnatal life as well [18]. The question is still under scrutiny, as it was later shown that some markers of meiosis-committed cells are highly expressed in the ovary of aged female mice in the absence of oocytes; moreover, by grafting an aged ovarian tissue from germ cell-specific transgenic mice into the ovary of a young wild-type host, the formation of GFP positive immature follicles has been demonstrated, along with the co-expression of NOBOX, a primordial oocyte marker [19]. It thus appears that the above mentioned definition of "true stem cells" should be based on the available genetic and molecular 
markers, which may constitute a kind of "signature" [20], together with a decisive functional aspect.

Among the different types of germ stem cells,we may first consider a set of cells destined to form mammalian gametes, called primordial germ cells (PGC's); they are determined early in embryogenesis and provide the special task of forming mammalian gametes; a series of studies were performed to understand the mechanism of PGC differentiation, as they appear closely related to embryonic stem cells and embryonic germ cells [21] [22]. Such connection is indeed apparent from studies on human embryonic germ cells (EGC's), pluripotent stem cells derived from primordial germ cells. EGCs demonstrate long-term self-renewal via clonal expansion in an undifferentiated state, but can differentiate in vitro to form so-called embryoid bodies, and then all three germ lineages, ectoderm, endoderm and esoderm [23].

Recent studies on EGC genetic complement provide a reliable model for identifying molecules involved in the pluripotent state when compared to their PGC progenitors and other pluripotent stem cells. Microarray studies and principal component analysis (PCA) have indeed shown for the first time that human EGCs possess a transcription profile distinct from PGCs and pluripotent stem cells. Studies with qRT-PCR have also revealed that human EGCs and PGCs express many pluripotency-associated genes but substantially different from ESC's and other cell types, like induced pluripotent stem cells and embryonal carcinoma cells; a few genes were found upregulated in PGCs which may help to distinguish their unipotent state [24]. These findings provide the first evidence of a possible genomic characterization of human germ cells and pluripotent stem cells and identify genes involved in different states of germ-line pluripotency.

\subsection{Embryonic Stem Cells (ES Cells)}

The components of the cells mass of the blastocyst which give rise to the foetus are called pluripotent embryonic stem cells commonly abbreviated ES cells [14]. ES cell lines can be isolated and propagated for long time in serum-free, properly supplemented media without a change in the karyotype, a pre-requisite for possible clinical use. When human ES cells are induced to differentiate, they give rise, like the EGC cells, to embryoid bodies which can evolve into various types of cells; the study of this process allows clarifying the regulation of lineage commitment and differentiation [17]. Moreover, ES cells have been proposed as a way of treatment in a wide range of human disorders, ranging from neurologic conditions to blood disorders, immune deficiencies and others, caused by lack or deficient number of certain cell types [4] [25].

It is however important to specify the nature of pluripotency; this is currently defined as the capacity of individual cells to initiate all lineages of the mature organism in response to signals from the embryo or cell culture environment; therefore a pluripotent cell represents a so called "ground state", free of epigenetic restriction and with minimal requirements for extrinsic stimuli [26]. It is also known that pluripotent stem cells have a distinct cell-cycle from differentiated cells as they exhibit long-term proliferative capacity by spending a shorter period of time in G1 and a proportionally longer period of time in S phase compared to adult cells [27].

ES cells can be maintained in culture in the presence of LIF and either BMP4. Under these conditions, numerous genes are expressed in a heterogeneous manner, implying that ESC cultures may harbor cells with distinct functional genome [28]-[30]. As far as ES cell development potential is concerned, it was generally accepted that ES cells are not totipotent as they cannot give rise to extra-embryonic tissues: recent data suggest anyway that mouse ES cells undergo a transient 2-cell phase, in which they can be really totipotent as they are able to originate placental tissue. It is still unknown whether, such 2-cell stage ES cells can form a live organism [31].

Among the latest developments about the properties of ES cells, there are interesting acquisitions on the mechanism for maintenance of pluripotency, in which three main transcription factors, Oct4, Sox2 and Nanog are involved: such factors are proteins that maintain ESC identity, but also decide germ layer fate. Oct4 suppresses neural ectodermal differentiation and promotes mesendodermal differentiation, while Sox2 inhibits mesendodermal differentiation and promotes neural ectodermal comversion [32].

Recent studies have also demonstrated that a key role in the pluripotency state is played by geminin, a protein which is involved in the control of the cell cycle and DNA replication [33]: in embryonic stem cells the deletion of the geminin gene quickly leads to a loss of pluripotency, and to differentiation into the mesendodermal direction with high Oct4/low Sox2 levels, while simultaneous loss of geminin and induction of the neural lineage cause apoptosis [34]. It is thus suggested that in early development geminin is required for Sox2 expression and thus for the maintenance of totipotency, pluripotency and the early neural lineage. 


\subsection{Haemopoietic Stem Cells}

Special consideration should be given to this type of stem cells, which are the most extensively studied stem cell type and have been for long time on the stage for their successful clinical application. As for their genesis, it was classically postulated that the first hematopoietic precursors reside within blood islands in the yolk sac (YS) so that they produce primitive erythrocytes which provide oxygen and nutrient delivery to the developing embryo. Primitive erythrocyte precursor colony-forming cells are first identified in murine YS as early as embryonic day (E) 7.0, but completely disappear by E9.0.; definitive erythropoiesis follows in a second wave, also arising in the YS and distinct from primitive erythropoiesis by the appearance of peculiar hemoglobin molecules; there is also production of the other cells of the haemopoietic compartment [35].

The stages of the complex process of HSC migration from the YS to the foetal liver (FL) and bone marrow (FBM) have been until recently largely unknown: there is present evidence that progenitor cells in the yolk sac are developmentally plastic and, when exposed to the correct microenvironment, have the potential to reconstitute all hematopoietic lineages in an adult mouse, after the onset of embryo circulation (9-10 dpc), [36]. It is however now envisaged that the principal site of definitive foetal multilineage hematopoiesis for vertebrates is the endothelium within the aorta-gonad-mesonephros (AGM) area, plus some role by the yolk sac and the placenta [37]. A critical and specific role of the GFI1 transcription factors has been suggested in the process leading to the generation of hematopoietic progenitors from hemogenic endothelium [38].

Early progenitors then colonize the fetal liver (FL), where they undergo expansion and maturation, so that from mid- to late gestation the FL becomes the major site of mammalian hematopoiesis; then haemopoietic progenitors colonize the fetal bone marrow, under the direction of several transcription programs, while the foetal spleen is initially seeded by progenitors that are unable to sustain myelopoiesis [39].

The identification of different types of HSC's has been based in the first place on various criteria, like biological activity, antigen markers and others [40]-[43]. Recently the development of immunodeficient mice, which allow an extensive monitoring of engrafted human cells opened the way to novel research: it has been for instance demonstrated that single HSC's, labeled by a a specific marker like C49f are highly efficient in generating long-term multilineage grafts [44].

Great attention was devoted to the identification of the molecular phenotype of the haemopoietic stem cells: these studies demonstrated a kind of genetic programme, comprising several thousands of gene products with regulatory function [45] [46]. As far as variations of gene assets in different types of stem cells is concerned, it was found that global gene expression profiling shows similarities and differences among mouse pluripotent stem cells of different origins and strains [47].

An interesting study compared the gene expression profiles of Lin-ckit+Sca-1+ (LKS) cells generated in vitro from mouse ESCs with that of native LKS cells isolated from mouse fetal liver (FL) or bone marrow (BM): it was found that in vitro - generated LKS cells were more similar to FL-than to BM LKS cells in gene expression and that, when compared to cells derived from bioreactor cultures, static culture-derived LKS cells showed fewer differentially expressed genes relative to both in vivo LKS populations. Overall, the expression of hematopoietic genes was lower in ESC-derived LKS cells compared to cells from BM and FL, while the levels of non-hematopoietic genes were up-regulated [48].

Recent studies have also addressed the mechanism of haemopoietic stem cell quiescence in the mouse bone marrow using three-dimensional imaging techniques: quiescent HSCs appear specifically linked with small arterioles that are preferentially found in endosteal bone marrow; these arterioles are associated with a special type of pericytes to form a niche, which is indispensabe for HSC maintenance [49].

\subsection{Induced Pluripotent Stem Cells (IPSC's)}

A few years ago, a team of Kyoto University in Japan reported that by adding a handful of genes to a skin cell, they could turn it into an induced pluripotent stem cell (IPSC), thus restoring the potential to develop new differentiated cells [50]. This was obtained by retroviral-mediated transduction of adult cells with four transcription factors, highly expressed in ES cells. After that report a remarkable progress followed, showing that IPSC' can be obtained by human adult cells and from a variety of tissues, including stomach and liver [51]. Beside the demonstration of a number of core transcription factors (OCT4, Nanog and Sox2), necessary to maintain pluripotency of ES cells, other factors have been identified, which can be used to induce reprogramming of cell differentiation in a number of somatic cells [52]. 
IPS cells have been extensively studied in the last years, with special regards to the early stages of their transformation and the sequence of events taking place in such stages. It was found that beside the before-mentioned transcription factors, other proteins are active in cell reprogramming, namely some epigenetic regulators, which promote the expression of quiescent pluripotency genes in fibroblasts: such factors, Parp1 and Tet2, are therefore the initiators of the reprogramming process [53]. The mechanism of epigenetic modeling for obtaining IPS cells has also been the subject of recent investigations and different models of cellular reprogramming have been discussed, with special attention to enzymes involved in this process [54]. It is actually postulated that the transition from differentiated cells to pluripotent cells follows a definite sequence, with evidence of two waves of gene regulations, as single-cell expression analysis during cellular reprogramming reveal an early stochastic and a late hierarchic phase [55]. The process seems to involve not only markers like CD 44 and C54, but also epidermis-related genes, an unexpected finding: it thus appears possible to delineate a sort of "road map" of the IPS cell generation pathway [56].

Contrasting reports have appeared on the immunogenicity of IPS cells. While a recent study supported this property, assessed by teratoma formation [57], another more recent report showed no difference in transplantation success between IPS-derived cells, as compared with ES-derived tissues, thus confirming a limited immunogenicity of both IPS and ES transplanted cells [58]. Serious consideration has been also given to assess the type of aneuploidy already evident in early passage IPSCs [59]. The effects of culture prolongation in highpassage pluripotent stem cells are actually due to gross chromosome abnormalities and other genetic modifications, which promote tumorigenic potential: this has therefore prompted a search for methods to remove prospective tumorigenic cells before transplantation, as proposed in recent investigations [60]. Other dangers associated with induction of pluripotency in somatic cells are examined in a recent review [61].

\subsection{Mesenchymal Stem Cells}

The initial realization that some kind of non-haemopoietic stem cells may be located in the bone marrow can be traced to the original hypothesis that hematopoietic stem cells (HSCs) are regulated by their physical association with a cellular microenvironment within BM: further investigations revealed that a second type of stem cell is present in the BM, specifically, in the hematopoiesis-supporting stroma [62]. In particular, Nestin ++ mesenchimal stem cells (MSC's) show a peculiar partnership with HSC's, to form a unique bone marrow niche [63].

Moreover, while the original notion of MSCs specifically referred to cells in BM (bone marrow stromal cells), the current notion has been extended to include cells from additional sources (such as synovium, adipose tissue, dental pulp, etc.) and indeed, from almost every postnatal connective tissue [64] [65].

At present, mesenchymal stem cells have been identified, in addition to bone marrow, in a number of adult tissues, including adipose tissue and fat pad. Mesenchymal stem cells are generally isolated from the tissue and expanded in culture: these cells are characterised or defined using a set of cell surface markers as they are generally positive for CD44, CD90 and CD105, and negative for haematopoetic markers CD34 and CD45 or the neurogenic marker CD56 [66].

An interesting part of the picture is some information suggesting that endothelium-adherent cells, so-called pericytes, may be candidate stem cell for the formation of vascular tissue cells: recent investigations have indeed identified, purified, and characterized distinct populations of MSC-like multilineage precursors from the vasculature of multiple human organs [67] [68]. These precursor cell subsets, derived from human blood vessels, include pericytes (PCs), adventitial cells (ACs), and myogenic endothelial cells (MECs), and may be isolated by fluorescence-activated cell sorting (FACS); purified PCs, ACs, and MECs not only exhibit typical mesodermal multipotency in culture but also demonstrate regenerative capacities in animal disease models [69].

The whole problem of the identity and function of MSC's, with special regard to species-specific differences in cell surface marker expression as well as their potential as therapeutic targets, has been the object of recent studies [70].

\subsection{Alternative Stem Cell Sources}

It has been known for many years that the skin contains a rather vast variety of stem cells, including epidermal and mesenchymal stem cells (MSCs), melanocytic stem cells derived from the embryonic neural crest, as well as haematopoietic and endothelial precursors [71]. Moreover, a distinct population of skin-derived progenitors has been isolated and characterized: these cells, named "skin-derived precursors (SKP), are neural crest precursors, 
located in an aspecific dermal niche and possessing a wide differentiation potential, which make them suitable for therapeutic use [72].

A recent example of how skin fibroblast-derived stem cells may be used in different area is supplied by a report from a team at the Mayo Clinic, which has obtained IPCS's from the skin of patients in end-stage kidney diseases; such iPCS's may be used not only for the study of renal disease pathogenesis but also as autologous elements, for a trial of kidney replacement therapy [73].

Among the adult cells which have been shown capable of reverting to a condition of IPCS's by appropriate in vitro treament, a very interesting place is occupied by mature adipose cells: their advantage is, of course, that they can be obtained in large amounts with minimal effort and can apparently maintain a kind of "staminal" characteristics during passage in culture, so that they may be eventually employed in attempts of tissue regeneration [74]; it has been shown indeed that purified adipose stem cells express high level of markers of staminality like CD49, CD44, CD90, CD105 and CD71 and that these markers are maintained at high level for at least 3 months and seven passages of in vitro culture [75]. Progenitor, endothelial and mesenchymal stem cells derived from adipose tissues may be considered for cell therapy in a number of disease conditions, including those affecting bone, cartilage, muscle, liver, kidney, cardiac, neural and pancreatic tissue [76].

An interesting source of stem cells has also received attention, namely the amniotic fluid: amniotic fluid-derived stem cells (AFSC) are easily collected, have a high renewal capacity and can differentiate into all tissues derived from all embryonic layers [77]. It has been recently confirmed that AFSC's can be maintained for over 250 population doubling, while preserving their telomere length and a normal karyotype: therefore many more uses for AFS's are now considered in regenerative medicine [78].

Another source, connected to amniotic fluid, is represented by placental stem cells, which are also available in considerable amount and show differentiation potential towards all three layers of germ cells [79] [80]; these foetal stem cells can be harvested in large numbers, and without the ethical concern attached to the use of embryonic stem cells. These stem cells may thus be a more practical source for regenerative medicine, particularly, if placentas are routinely saved instead of thrown away [81].

\subsection{Cancer Stem Cells}

Early ideas on the potential existence of cancer stem cells(CSC's) emerged before the end of last century, in parallel with research on embryonic stem cells, resulting in a deeper knowledge on stem cells in general. The early information on cancer stem cell was founded on research in acute myeloid leukaemia (AML): it was actually shown that leukemic blasts in AML originate from precursor cells in the bone marrow carrying a specific genomic DNA mutation, called leukemia initiating mutation, while during progression of the disease multiple mutations follow [82]. Leukemic mutated cells are highly resistant to chemotherapy and are responsible for the recurrence of AML after an initial complete remission: even after chemotherapy they retain their self-renewal capacity, so that they can rapidly replenish the leukemic cell population, leading to recurrence of the disease [83].

In the general field of oncogenesis, the present theory postulates that CSC's derive from the switch from a polarized epithelial type to a non-polarized mesenchymal cell type with stem cell properties, including migratory behavior, self renewal and generation of differentiated cellularity. This process, called epithelial-mesenchymaltransition or EMT, shows some striking and fascinating similarities to processes taking place during embryonic life, which allows cell migration to the right body location in the developing embryo; in the same way, a combination of genomic changes and biochemical and physical interactions with its microenvironment, leads an epithelial cancer cell to become a cancer stem cell [84] [85].

An interesting development has been recently reported, namely the identification of gene sets which control growth and survival of leukemic stem cells: such genes have influence on multiple aspects of leukemia biology and on the interaction of malignant cells with the surrounding microenvironment, so that a kind of CML signature may be obtained; it is significant that compounds with predicted inhibitory activity toward the CML signature show a specific cytotoxicity in both mouse and human cells [86].

Moreover it has recently emerged that stem cells from Chronic Myeloid Leukemia (CML) are controlled in their properties by a set of proteins, called Sirtuins, a subclass of histone deacetylases acting on a variety of cellular processes, like DNA repair, cell survival and metabolism [87]: experiments in transgenic leukemic mice have shown that treatment with Tenovin, a sirtuin family inhibitor [88], causes a significant loss of CML stem cells and even more so when Tenovin is associated with the well-known anti-leukemic compound imatinib [89]. It may thus become possible for the first time to act on highly resistant cancer cells. 


\section{Clinical Applications and New Issues}

Stem cell therapy has been an ever-expanding area since the early days and it only possible in the present survey to mention a few landmarks as well as outlining new developments (see Table 1).

First of all, it is proper to recall the now historical trials of stem cell therapy, namely haemopoietic cell transplantation (HST), performed by the team led by Nobel Prize winner D. Thomas [90]; scientists in many Countries have contributed to the development of such technique, using stem cells from different sources: for instance a successful use of peripheral blood stem cells, with the added bonus of their mobilization before collection, has been established [91]. Stem cells from the umbilical vein, or cord blood (CB) stem cells, have also been collected in considerable amount and used for transplantation [92]; CB banks have been also set up, applying strict rules for a correct collection and preservation of samples [93]. It is important to add that applications of HST in clinical haematology have actually increased enormously from the primitive area of blood malignancies to red cell anomalies like severe haemoglobino-pathies and a number of other disorders [94].

The therapeutic potential of stem cell treatment in neurological disorders is so relevant that we can only mention some of them. Disease-specific IPSC's were derived from patients of several neurodegenerative diseases, including Parkinson's disease, Alzheimer's disease, amyotrophic lateral sclerosis and spinal muscular atrophy; neurons differentiated from these IPSC's reproduce the actual pathological features and thus allow both a test for drug activity and a model for cell replacement [95].

A good example is Parkinson's disease (PD), where gene therapy is aiming to provide the missing chemical, dopamine and other components, to the affected cells: clinical trials include the attempts to insert useful genes for production, storage and uptake of dopamine by the dopaminergic pathways of the basal ganglia in the brain. Research using human IPSC's derived from PD patients showed indeed that transplanted differentiated cells were able to survive, engraft and differentiate into dopaminergic neurons of adult rodents, with favorable functional effects [96]. Long-term survival of the transplanted cells was also detected and no evidence of PD pathology, such as inclusion body formation, was observed in the transplanted neurons [97].

Attempts at stem cell treatment are also envisaged for diabetes: in order to generate functional insulin-producing cells, embryonic stem cells cell must first differentiate to endoderm and pancreatic endocrine progenitors; in this process, activin A (a member of the transforming growth factor- $\beta$ superfamily) has shown a remarkable activity [98].

An interesting protocol, carried out in a serum-free system, has been described, by which human embryonic (ES) cells are induced to differentiate into functional insulin-producing cells: activin A is used in the initial stage to induce definitive endoderm lineage differentiation from human ES cells, while all-trans retinoic acid (RA) is then utilized to promote pancreatic differentiation; final maturation is induced by fibroblast growth factors and nicotinamide, so that the differentiated cells express islet specific markers [99].

As far as cardiac tissue renewal is concerned, recent efforts have shown a remarkable progress, with the demonstration that cardiac fibroblasts can be reprogrammed in vitro to new differentiated cells like cardiomyocytes, by appropriate cocktails of transcription factors [100]. Moreover, two different teams, after inducing

\section{Table 1. Stem cell applications.}

1) Haemopoietic stem cell transplantation
A) Haematological malignancies
B) Severe Haemoglobinopathies
C) Aplastic anemia
D) Primary immune deficiencies

2) Stem cells delivery for tissue regeneration
A) Neurological diseases
B) Diabetes
C) Cardiac failure
D) Cartilage and bone disorders
E) Skin and skin-appendage disorders
F) Others

3) Stem cells as vectors for gene therapy

Delivery of a therapeutic gene to the desired cell type by genetically transduced hemopoietic stem cells 
myocardial infarction in experimental mice, inserted by retroviral transduction the genes encoding 4 transcription factors (GATA 4, MEF2Cl, Tbx5 and HAND2)into the injured area, in order to produce cardiomyocyte-like cells in vivo; after a few weeks, the new cells were actively proliferating and helping to improve the cardiac function [101] [102].

A very recent development has been the realization that mitochondrial fusion is required for proper cardiomyocyte development: it has been indeed found that ablation of mitochondrial fusion proteins Mitofusin 1 and 2 in the embryonic mouse heart, or gene-trapping of Mitofusin 2 in mouse embryonic stem cells (ESCs), cause arrest of mouse heart development and stops differentiation of ESCs into cardiomyocytes. It appears therefore that cardiomiocyte differentiation is a complex process, requiring mitochondria, $\mathrm{Ca}^{2+}$, and calcineurin interacting with Notch1 signaling [103].

Cartilage defects have also been treated for some time with cell therapy using autologous chondrocyte transplantation (ACT): a new generation of ACT techniques, where cells are combined with resorbable biomaterials, like suspended cultured chondrocytes with a collagen type I/III membrane, has been employed [104]. Moreover it ha been possible to identify (among 22.000 tested) a molecule that promotes the selective differentiation of multipotent mesenchymal stem cells: this compound, called "kartogenin, is active in animal models of cartilage defects and is now tested in human trials [105].

Numerous other tissues and organs have been the object of research in order to regenerate their constituents: successful trials have been carried out, for instance, for the treatment of skin lesions and disorders, including skin wounds [106]. Ectodermal tissues, like hair and teeth, have also been the object of reparative medicine [107] [108].

New issues are presently discussed among scientists studying the dynamics of stem cell and their possible applications: main focus is now projected on induced pluripotent cells, which offer a vast potential of opportunities, but also present some limitations. The first one is the modest efficiency of somatic cells reprogramming, despite the variety of chromatin modifiers which are employed to produce authentic IPSC's [109].

Another drawback is the lack of certainty about the outcome of the operation when the classical transcription factors are applied to induce IPS production. Therefore, in order to obtain a more controlled outcome, it is necessary to study those factors causing such variability of results. In this field progress is now being made. A recent report demonstrates the existence of a repressor complex, named as Mbd3/NuRD (nucleosone remodeling and deacetylacetion complex), capable of inhibiting the reprogramming process, so that depletion of its crucial constituent Mbd3 induces IPSC production to a near 100\% efficiency from both mouse and human cells [110].

Another development is the search to generate through reprogramming stem cells with good transplantable potential. A possible shortcut might be a conversion from related lineages in order to minimize the "epigenetic distance" to a desired cell type; for instance, haemopoietic transplantable stem cells may be obtained by a strategy to respecify lineage-restricted CD34(+) CD45(+) myeloid precursors derived from haemopoietic PSCs into multilineage progenitors that can be expanded in vitro and engrafted in vivo [111]. If it is however difficult to obtain this cellular transformation in vitro, it is suggested to carry on the conversion directly in vivo: as beforementioned, direct transduction into a damaged heart of the relevant genes may produce cardiomyocytes with a better function, compared to the in vitro reprogrammed counterparts [112].

An important achievement has been announced recently, namely the derivation of stem cells from cloned human embryos: embryonic stem cell lines, obtained by nuclear transfer from "premium” oocytes displayed normal diploid karyotypes and inherited their nuclear genome exclusively from parental somatic cells. Some experiments have suggested that, at least in mice, ES cells from cloned embryos might be of better quality than IPS cells [113].

A final word should be pronounced about safety of possible applications: doubts have been raised particularly concerning the problems from IPSCs, like the possible genetic alterations introduced by reprogramming, as it was reported that there were significantly more copy number variations in IPSCs, as compared to ES's or donor fibroblasts, a diversity formed perhaps de novo during the process; however, it was recently found that most variations were not consequences of reprogramming, but rather a pre-existing genetic diversification in rare somatic cells; it is now therefore claimed that IPSCs may still be safe in delivering personalized cell treatment [114].

\section{Conclusions}

The evidence of organ and tissue repair in small animals, like the regeneration of snail tails, as well as salaman- 
dra limbs and eyes was described with amiable envy by the Italian 18th century naturalist Spallanzani [115] but was then considered as an impossible dream for humans.

An impressive amount of research in recent time has however introduced the concept of cell and tissue regeneration, thanks to the isolation and manipulation of various types of stem cells. Furthermore, recent investigations have revealed that it is not impossible to simulate the developmental potential of embryonic cells, which gives rise to all differentiated cells in the organism: a variety of somatic cells may be actually induced to reconverte to a different fate, culminating in a diverse kind of terminal cell. Paying due attention to avoid possible damage from untested procedures, there is therefore a great potential for numerous and sometimes unpredictable applications in regenerative medicine.

\section{Statement}

The author declines any potential conflict of interest.

\section{References}

[1] Lajtha, L. (1979) Stem Cell Concepts. Differentiation, 14, 23-34. http://dx.doi.org/10.1111/j.1432-0436.1979.tb01007.x

[2] Weissman, I.L. (2009) Stem Cells: Units of Development, Units of Regeneration, and Units in Evolution. Cell, 100, 157-168. http://dx.doi.org/10.1016/S0092-8674(00)81692-X

[3] Eridani, S. (2002) Stem Cells for All Seasons? Experimental and Clinical Issues. Journal of the Royal Society of Medicine, 95, 5-8. http://dx.doi.org/10.1258/jrsm.95.1.5

[4] Besser, D. (2012) Stem Cell Biology_From Basic Research to Regenerative Medicine. Journal of Molecular Medicine, 90, 731-733. http://dx.doi.org/10.1007/s00109-012-0929-5

[5] Roselli, E.A., Mezzadra, R., Frittoli, M.C., et al. (2010) Correction of Beta-Thalassemia Major by Gene Transfer in Haematopoietic Progenitors of Pediatric Patients. EMBO Molecular Medicine, 8, 315-328.

http://dx.doi.org/10.1002/emmm.201000083

[6] Jacobson, L.O., Marks, E.K., Robson, M.J., et al. (1949) The Effect of Spleen Protection on Mortality Following X-Irradiation. Journal of Laboratory and Clinical Medicine, 34, 1538-1543.

[7] Lorenz, E., Uphoff, D., Reid, T.R. and Shelton, E. (1951) Modification of Irradiation Injury in Mice and Guinea Pigs by Bone Marrow Injections. Journal of the National Cancer Institute, 12, 197-201.

[8] Ford, C.E., Hamerton, J.L., et al. (1956) Cytological Identification of Radiation-Chimaeras. Nature, 177, $452-454$. http://dx.doi.org/10.1038/177452a0

[9] Till, J.E. and McCulloch, E.A. (1961) A Direct Measurement of the Radiation Sensitivity of Normal Mouse Bone Marrow Cells. Radiation Research, 14, 213-222. http://dx.doi.org/10.2307/3570892

[10] Siminovitch, L., McCulloch, E.A. and Till, J.E. (1963) The Distribution of Colony-Forming Cells among Spleen Colonies. Journal of Comparative Physiology, 62, 327-336. http://dx.doi.org/10.1002/jcp.1030620313

[11] McCulloch, E.A. and Till, J.E. (2005) Perspectives on the Properties of Stem Cells. Nature Medicine, 11, $1026-1028$. http://dx.doi.org/10.1038/nm1005-1026

[12] Morrison, S.J. and Weissman, I.L. (1994) The Long-Term Repopulating Subset of Hematopoietic Stem Cells Is Deterministic and Isolatable by Phenotype. Immunity, 1, 661-673. http://dx.doi.org/10.1016/1074-7613(94)90037-X

[13] Evans, M.J. (1981) Establishment in Culture of Pluripotential Cells from Mouse Embryos. Nature, 292, $154-156$. http://dx.doi.org/10.1038/292154a0

[14] Thomson, J.A., Itskovitz-Eldor, J., Shapiro, S.S., et al. (1998) Embryonic Stem Cells Derived from Human Blastocysts. Science, 282, 1145-1147. http://dx.doi.org/10.1126/science.282.5391.1145

[15] Kerr, C.L., Gearhart, J.D., Elliott, A.M. and Donovan, P.J. (2006) Embryonic Germ Cells: When Germ Cells Become Stem Cells. Seminars in Reproductive Medicine, 24, 304-313. http://dx.doi.org/10.1055/s-2006-952152

[16] Moore, M.A.S. and Metcalf, D. (1970) Ontogeny of the Haemopoietic System. British Journal of Haematology, 18, 279-296. http://dx.doi.org/10.1111/j.1365-2141.1970.tb01443.x

[17] Weissman, I. (2000) Stem Cells: Units of Development, Units of Regeneration, and Units in Evolution. Cell, 100, 157168. http://dx.doi.org/10.1016/S0092-8674(00)81692-X

[18] Johnson1, J., Canning, J., Kaneko, T., Pru, J.K. and Tilly, J.K. (2004) Germline Stem Cells and Follicular Renewal in the Postnatal Mammalian Ovary. Nature, 428, 145-150.

[19] Niikura, Y., Niikura, T. and Tilly, J.L. (2009) Aged Mouse Ovaries Possess Rare Premeiotic Germ Cells That Can 
Generate Oocyte Following Transplantation into a Young Host Environment. Aging, 1, 971-978.

[20] Ivanova, N., Dimos, J., Schaniel, C., Hackney, J., Moore, K. and Lemischka, I. (2002) A Stem Cell Molecular Signature. Science, 298, 601-604. http://dx.doi.org/10.1126/science.1073823

[21] Alberts, B., Johnson, A. and Lewis, J., et al. (2002) Primordial Germ Cells and Determination in Mammals. Molecular Biology of the Cell. Garland Science.

[22] Aflatoonian, B., Ruban, L., Jones, M., et al. (2009) In Vitro Post-Meiotic Germ Cell Development from Human Embryonic Stem Cells. Human Reproduction, 24, 3150-3159.

[23] Itskovitz-Eldor, J., Schuldiner, M., Karsenti, D., et al. (2000) Differentiation of Human Embryonic Stem Cells into Embryoid Bodies Comprising the Three Embryonic Germ Layers. Molecular Medicine, 6, 88-95.

[24] Pashai, N., Hao, H., All, A., Gupta, S., Chaerkady, R., et al. (2012) Genome-Wide Profiling of Pluripotent Cells Reveals a Unique Molecular Signature of Human Embryonic Germ Cells. PLoS ONE, 7, e39088. http://dx.doi.org/10.1371/journal.pone.0039088

[25] Eridani, S., Sgaramella, V. and Cova, L. (2004) Stem Cells: From Embryology to Cellular Therapy? An Appraisal of the Present State of Art. Cytotechnology, 44, 125-141. http://dx.doi.org/10.1007/s10616-004-2067-6

[26] Wray, J., Kalkan, T. and Smith, A.G. (2010) The Ground State of Pluripotency. Biochemical Society Transactions, 38, 1027-1032. http://dx.doi.org/10.1042/BST0381027

[27] Philipczyk, A.A., Laslett, A.L., Mummery, C. and Pera, M.F. (2007) Differentiation Is Coupled to Changes in the Cell Cycle Regulatory Apparatus of Human Embryonic Stem Cells. Stem Cell Research, 1, 45-60. http://dx.doi.org/10.1016/j.scr.2007.09.002

[28] Niakan, K.K., Ji, H., Maher, R., et al. (2010) Sox17 Promotes Differentiation in Mouse Embryonic Stem Cells by Directly Regulating Extraembryonic Gene Expression and Indirectly Antagonizing Self-Renewal. Genes \& Development, 24, 312-326.

[29] Hayashi, K., Lopes, S.M., Tang, F. and Surani, M.A. (2008) Dynamic Equilibrium and Heterogeneity of Mouse Pluripotent Stem Cells with Distinct Functional and Epigenetic States. Cell Stem Cell, 3, 391-401. http://dx.doi.org/10.1016/j.stem.2008.07.027

[30] Singh, A.M., Hamazaki, T., Hankowski, K.E. and Terada, N. (2007) A Heterogeneous Expression Pattern for Nanog in Embryonic Stem Cells. Stem Cells, 25, 2534-2542. http://dx.doi.org/10.1634/stemcells.2007-0126

[31] Macfarlan, T.S., Gifford, W.D., Driscoll, S., et al. (2012) Embryonic Stem Cell Potency Fluctuates with Endogenous Retrovirus Activity. Nature, 487, 57-63.

[32] Thomson, M., Liu, S.J., Zou, L.N., et al. (2011) Pluripotency Factors in Embryonic Stem Cells Regulate Differentiation into Germ Layers. Cell, 145, 875-889.

[33] Gonzalez, M.A., Tachibana, K.E., Adams, D.J., et al. (2006) Geminin is Essential to Prevent Endoreduplication and to Form Pluripotent Cells during Mammalian Development. Genes \& Development, 20, 1880-1884. http://dx.doi.org/10.1101/gad.379706

[34] Tabrizi, G.A., Böse, K., Reimann, Y. and Kessel, M. (2013) Geminin Is Required for the Maintenance of Pluripotency. PLoS ONE, 8, e73826. http://dx.doi.org/10.1371/journal.pone.0073826

[35] Baron M.H., Isern J. and Fraser S.T. (2012) The Embryonic Origins of Erythropoiesis in Mammals. Blood, 119, 4828-4837. http://dx.doi.org/10.1182/blood-2012-01-153486

[36] Yoder, M.C., Hiatt, K. and Mukherjee, P. (1997) In Vivo Repopulaing Hematopoietic Stem Cells Are Present in the Murine Yolk Sac at Day 9.0 Postcoitus. Proceedings of the National Academy of Sciences of the United States of America, 94, 6776-6780. http://dx.doi.org/10.1073/pnas.94.13.6776

[37] Zovein, A.C., Hofmann, J.J., Lynch, M., et al. (2008) Fate Tracing Reveals the Endothelial Origin of Hematopoietic Stem Cells. Cell Stem Cell, 3, 625-636. http://dx.doi.org/10.1016/j.stem.2008.09.018

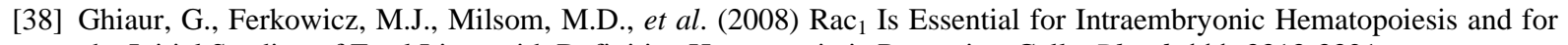
the Initial Seeding of Fetal Liver with Definitive Hematopoietic Progenitor Cells. Blood, 111, 3313-3321. http://dx.doi.org/10.1182/blood-2007-08-110114

[39] Ciriza, J., Thompson, H., Petrosian, R., et al. (2013) The Migration of Hematopoietic Progenitors from the Fetal Liver to the Fetal Bone Marrow: Lessons Learned and Possible Clinical Applications. Experimental Hematology, 41, 411-423. http://dx.doi.org/10.1016/j.exphem.2013.01.009

[40] Eridani, S. and Morali, F. (1993) Identification of Haemopoietic Stem Cells. Cytotechnology, 11, 101-106. http://dx.doi.org/10.1007/BF00748998

[41] Eridani, S. (2002) Stem Cells for All Seasons? Experimental and Clinical Issues. Journal of the Royal Society of Medicine, 95, 5-8. http://dx.doi.org/10.1258/jrsm.95.1.5 
[42] Morrison, S.J., Wandycz, A.M., Hemmati, H.D., Wright, D.E. and Weissman, I.L. (1997) Identification of a Lineage of Multipotent Hematopoietic Progenitors. Development, 124, 1929-1939.

[43] Majeti, R., Park, C.Y. and Weissman, I.L. (2007) Identification of a Hierarchy of Multipotent Hematopoietic Progenitors in Human Cord Blood. Cell Stem Cell, 1, 635-645. http://dx.doi.org/10.1016/j.stem.2007.10.001

[44] Notta, F., Doulatov, S., Laurenti, E., Poeppl, A., Jurisica, I. and Dick, J.E. (2011) Isolation of Single Human Hematopoietic Stem Cells Capable of Long-Term Multilineage Engraftment. Science, 333, 218-221. http://dx.doi.org/10.1126/science.1201219

[45] Phillips, R.L., Ernst, R.E., Brunk, B., Ivanova, N., Mahan, M.A., et al. (2000) The Genetic Program of Hematopoietic Stem Cells. Science, 288, 1635-1640. http://dx.doi.org/10.1126/science.288.5471.1635

[46] Chambers, S.M., Boles, N.C., Lynk, K., et al. (2007) Hematopoietic Fingerprints: An Expression Database of Stem Cells and Their Progeny. Cell Stem Cell, 1, 578-591. http://dx.doi.org/10.1016/j.stem.2007.10.003

[47] Sharova, L.V., Sharov, A.A., Piao, Y., et al. (2007) Global Gene Expression Profiling Reveals Similarities and Differences among Mouse Pluripotent Stem Cells of Different Origins and Strains. Developmental Biology, 307, 446-459. http://dx.doi.org/10.1016/j.ydbio.2007.05.004

[48] Fernandez, I., Krista, M., Fridley, K.M., et al. (2012) Gene Expression Profile and Functionality of ESC-Derived Lin-ckit+Sca-1+ Cells Are Distinct from Lin-ckit+Sca-1+ Cells Isolated from Fetal Liver or Bone Marrow. PLoS ONE, 7, e51944. http://dx.doi.org/10.1371/journal.pone.0051944

[49] Kunisaki, Y., Bruns, I., Scheiermann, C., et al. (2013) Arteriolar Niches Maintain Haematopoietic Stem Cell Quiescence. Nature, 502, 637-642.

[50] Takahashi, K. and Yamanaka, S. (2006) Induction of Pluripotent Stem Cells from Mouse Embryonic and Adult Fibroblast Cultures by Defined Factors. Cell, 126, 663-676. http://dx.doi.org/10.1016/j.cell.2006.07.024

[51] Aoi, T., Yae, K., Nakagawa, M., et al. (2008) Generation of Pluripotent Stem Cells from Adult Mouse Liver and Stomach Cells. Science, 321, 699-702. http://dx.doi.org/10.1126/science.1154884

[52] Park, I.H., West, J.A., et al. (2008) Reprogramming of Human Somatic Cells to Pluripotency with Defined Factors. Nature, 451, 141-146.

[53] Doege, C.A., Inoue, K., Yamashita, T., et al. (2012) Early-Stage Epigenetic Modification during Somatic Cell Reprogramming by Parp1 and Tet2. Nature, 488, 652-655.

[54] Cantone, I. and Fisher, A.G. (2013) Epigenetic Programming and Reprogramming during Development. Nature Structural \& Molecular Biology, 20, 282-289.

[55] Buganim, Y., Faddah, D.A., Cheng, A.W., et al. (2012) Single-Cell Expression Analyses during Cellular Reprogramming Reveal an Early Stochastic and a Late Hierarchic Phase. Cell, 150, 1209-1222. http://dx.doi.org/10.1016/j.cell.2012.08.023

[56] O’Malley, J., Skylaki, S., Iwabuchi, K.A., Chantoura, E., et al. (2013) High-Resolution Analysis with Novel Cell-Surface Markers Identifies Routes to iPS Cells. Nature, 499, 88-91.

[57] Zhao, T., Zhang, Z.N., Rong, Z. and Xu, Y. (2011) Immunogenicity of Induced Pluripotent Stem Cells. Nature, 474, 212-215.

[58] Araki, R., Uda, M., Hoki, Y., Sunayama, M., et al. (2013) Negligible Immunogenicity of Terminally Differentiated Cells Derived from Induced Pluripotent or Embryonic Stem Cells. Nature, 494, 100-104.

[59] Mayshar, Y., Ben-David U., Lavon N., Biancotti J., et al. (2010) Identification and Classification of Chromosomal Aberrations in Human Induced Pluripotent Stem Cells. Cell Stem Cell, 7, 521-531. http://dx.doi.org/10.1016/j.stem.2010.07.017

[60] Ben-David, U., Nudel, N. and Benvenisty, N. (2013) Immunologic and Chemical Targeting of the Tight-Junction Protein Claudin-6 Eliminates Tumorigenic Human Pluripotent Stem Cells. Nature Communications, 4, 1992.

[61] Lee, A.S., Tang, C., Rao, M.S., Weissman, I.L. and Wu, J.C. (2013) Tumorigenicity as a Clinical Hurdle for Pluripotent Stem Cell Therapies. Nature Medicine, 19, 998-1004.

[62] Simmons, P.J. and Torok-Storb, B. (1991) Identification of Stromal Cell Precursors in Human Bone Marrow by a Novel Monoclonal Antibody, STRO-1. Blood, 78, 55-62.

[63] Méndez-Ferrer, S., Michurina, T., Ferraro, F., et al. (2010) Mesenchymal and Haematopoietic Stem Cells Form a Unique Bone Marrow Niche. Nature, 466, 829-834.

[64] Chamberlain, G., Fox, J., Ashton, B. and Middleton, J. (2007) Concise Review: Mesenchymal Stem Cells: Their Phenotype, Differentiation Capacity, Immunological Features, and Potential for Homing. Stem Cells, 25, 2739-2749. http://dx.doi.org/10.1634/stemcells.2007-0197

[65] Bianco, P., Robey, P.G. and Simmons, P.J. (2008) Mesenchymal Stem Cells: Revisiting History, Concepts, and Assays. 
Cell Stem Cell, 2, 313-319. http://dx.doi.org/10.1016/j.stem.2008.03.002

[66] Khan, W.S. and Hardingham, T.E. (2012) The Characterisation of Mesenchymal Stem Cells: A Stem Cell Is Not a Stem Cell Is Not a Stem Cell. Journal of Stem Cells, 7, 87-95.

[67] Tavian, M., Zheng, B., Oberlin, E., et al. (2005) The Vascular Wall as a Source of Stem Cells. Annals of the New York Academy of Sciences, 1044, 41-50. http://dx.doi.org/10.1196/annals.1349.006

[68] Armulik, A., Genové, G. and Betsholtz, C. (2011) Pericytes: Developmental, Physiological, and Pathological Perspectives, Problems, and Promises. Developmental Cell, 21, 193-215. http://dx.doi.org/10.1016/j.devcel.2011.07.001

[69] Chen, W.C., Park, T.S., Murray, I.R., et al. (2013) Cellular Kinetics of Perivascular MSC Precursors. Stem Cells International, 2013, 983059. http://dx.doi.org/10.1155/2013/983059

[70] Bianco, P., Cao, X., Frenette, P., et al. (2013) The Meaning, the Sense and the Significance: Translating the Science of Mesenchymal Stem Cells into Medicine. Nature Medicine, 19, 35-42.

[71] Bartsch, G., Yoo, J.J., De Coppi, P., et al. (2005) Propagation, Expansion, and Multilineage Differentiation of Human Somatic Stem Cells from Dermal Progenitors. Stem Cells and Development, 14, 337-348. http://dx.doi.org/10.1089/scd.2005.14.337

[72] Fernandes, K.J.L., Toma, J.G. and Miller, F.D. (2008) Multipotent Skin-Derived Precursors: Adult Neural Crest-Related Precursors with Therapeutic Potential. Philosophical Transactions of the Royal Society B, 363, 185-198. http://dx.doi.org/10.1098/rstb.2006.2020

[73] Thatava, T., Armstrong, A.S., Sakuma, T., et al. (2011) Successful Disease-Specific Induced Pluripotent Stem Cell Generation from Patients with Kidney Transplantation. Stem Cell Research \& Therapy, 2, 48. http://dx.doi.org/10.1186/scrt89

[74] Oedayrajsinghe-Varma, M.J., Breuls, R.G., et al. (2007) Phenotypical and Functional Characterization of Freshly Isolated Adipose Tissue-Derived Stem Cells. Stem Cells and Development, 16, 91-104. http://dx.doi.org/10.1089/scd.2006.0026

[75] Folgiero, V., Migliano, E., Marinella, T., et al. (2010) Purification and Characterization of Adipose-Derived Stem Cells from Patients with Lipoaspirate Transplant. Cell Transplantation, 19, 1225-1235. http://dx.doi.org/10.3727/09638910X519265

[76] Tremolada, C., Palmieri, G. and Ricordi, C. (2010) Adipocyte Transplantation and Stem Cells: Plastic Surgery Meets Regenerative Medicine. Cell Transplantation, 19, 1217-1223. http://dx.doi.org/10.3727/096368910X507187

[77] Kim, J., Lee, Y., Kim, H., et al. (2007) Human Amniotic Fluid-Derived Stem Cells Have Characteristics of Multipotent Stem Cells. Cell Proliferation, 40, 75-90. http://dx.doi.org/10.1111/j.1365-2184.2007.00414.x

[78] Joo, S., Ko, I.K., Atala, A., Yoo, J.J. and Lee, S.J. (2012) Amniotic Fluid-Derived Stem Cells in Regenerative Medicine Research. Archives of Pharmacal Research, 35, 271-280. http://dx.doi.org/10.1007/s12272-012-0207-7

[79] Yen, B.L., Huang, H.I., Chien, C.C., et al. (2005) Isolation of Multipotent Cells from Human Term Placenta. Stem Cells, 23, 3-9. http://dx.doi.org/10.1634/stemcells.2004-0098

[80] Parolini, O., Alviano, F., Bagnara, G.P., et al. (2008) Concise Review: Isolation and Characterization of Cells from Human Term Placenta: Outcome of the First International Workshop on Placenta Derived Stem Cells. Stem Cells, 26, 300-311. http://dx.doi.org/10.1634/stemcells.2007-0594

[81] Nazarov, I., Lee, J.W., Soupene, E., et al. (2012) Multipotent Stromal Stem Cells from Human Placenta Demonstrate High Therapeutic Potential. Stem Cells Translational Medicine, 1, 359-372. http://dx.doi.org/10.5966/sctm.2011-0021

[82] Dick, J.E. (2008) Stem Cell Concepts Renew Cancer Research. Blood, 112, 4793-4805. http://dx.doi.org/10.1182/blood-2008-08-077941

[83] Lane, S.W. and Gilliland, D.G. (2010) Leukemia Stem Cells. Seminars in Cancer Biology, 20, 71-76. http://dx.doi.org/10.1016/j.semcancer.2009.12.001

[84] Scheel, C. and Weinberg, R.A. (2012) Cancer Stem Cells and Epithelial-Mesenchymal Transition: Concepts and Molecular Links. Seminars in Cancer Biology, 22, 396-403. http://dx.doi.org/10.1016/j.semcancer.2012.04.001

[85] van de Stolpe, A. (2013) On the Origin and Destination of Cancer Stem Cells: A Conceptual Evaluation. American Journal of Cancer Research, 3, 107-116.

[86] Ashton, J.M., Balys, M., Neering, S.J., et al. (2012) Gene Sets Identified with Oncogene Cooperativity Analysis Regulate In Vivo Growth and Survival of Leukemia Stem Cells. Cell Stem Cell, 11, 359-372. http://dx.doi.org/10.1016/j.stem.2012.05.024

[87] Halgis, M.C., Sinclair, D.A. (2010) Mammalian Sirtuins: Biological Insights and Disease Relevance. Annual Review of Pathology: Mechanisms of Disease, 5, 253-295. http://dx.doi.org/10.1146/annurev.pathol.4.110807.092250

[88] Lain, S., Hollick, J.J., et al. (2008) Discovery, in Vivo Activity, and Mechanism of Action of a Small-Molecule p53 Ac- 
tivator. Cancer Cell, 13, 454-463. http://dx.doi.org/10.1016/j.ccr.2008.03.004

[89] Ito, T., Zimdahl, B. and Reya, T. (2012) Asirting Control over Cancer Stem Cells. Cancer Cell, 21, 140-142. http://dx.doi.org/10.1016/j.ccr.2012.01.014

[90] Thomas, E.D., Storb, R., Clift, R.A., et al. (1975) Bone-Marrow Transplantation. New England Journal of Medicine, 292, 832-843.

[91] Cutler, C. and Antin, J.H. (2001) Peripheral Blood Stem Cells for Allogeneic Transplantation: A Review. Stem Cells, 19, 108-117. http://dx.doi.org/10.1634/stemcells.19-2-108

[92] Eridani, S., Mazza, U., Massaro, P., et al. (1998) Cytokine Effect on ex Vivo Expansion of Haematopoietic Stem Cells of Different Human Sources. Biotherapy, 11, 291-296. http://dx.doi.org/10.1023/A:1008081708054

[93] Rubinstein, P. (2009) Cord Blood Banking for Clinical Transplantation. Bone Marrow Transplant, 44, 635-642. http://dx.doi.org/10.1038/bmt.2009.281

[94] Roifman, C.M., Fischer, A., Notarangelo, L.D., et al. (2010) Indications for Hemopoietic Stem Cell Transplantation. Immunology and Allergy Clinics of North America, 30, 261-262. http://dx.doi.org/10.1016/j.iac.2010.03.004

[95] Jung, Y.W., Hysolli, E., Kim, K.Y., Tanaka, Y. and Park, I. (2012) Human Induced Pluripotent Stem Cells and Neurodegenerative Disease: Prospects for Novel Therapies. Current Opinion in Neurology, 25, 125-130. http://dx.doi.org/10.1097/WCO.0b013e3283518226

[96] Tailor, J., Andreska, T. and Kittappa, R. (2012) From Stem Cells to Dopamine Neurons: Developmental Biology Meets Neurodegeneration. CNS \& Neurological Disorders-Drug Targets, 11, 893-896. http://dx.doi.org/10.2174/1871527311201070893

[97] Hargus, G., Cooper, O., Deleidi, M., et al. (2010) Differentiated Parkinson Patient-Derived Induced Pluripotent Stem Cells Grow in the Adult Rodent Brain and Reduce Motor Asymmetry in Parkinsonian Rats. Proceedings of the National Academy of Sciences of the United States of America, 107, 15921-15926. http://dx.doi.org/10.1073/pnas.1010209107

[98] Sulzbacher, S., Schroeder, I.S., Truong, T.T. and Wobus, A.M. (2009) Activin A-Induced Differentiation of Embryonic Stem Cells into Endoderm and Pancreatic Progenitors-The Influence of Differentiation Factors and Culture Conditions. Stem Cell Reviews and Reports, 5, 159-173. http://dx.doi.org/10.1007/s12015-009-9061-5

[99] Yan, S. (2010) Generation of Functional Insulin-Producing Cells from Human Embryonic Stem Cells in Vitro. Methods in Molecular Biology, 636, 79-85. http://dx.doi.org/10.1007/978-1-60761-691-7_5

[100] Ieda, M., Fu, J.D., Delgado-Olguin, P., et al. (2010) Direct Reprogramming of Fibroblasts into Functional Cardiomyocytes by Defined Factors. Cell, 142, 375-386. http://dx.doi.org/10.1016/j.cell.2010.07.002

[101] Qian, L., Huang Y., Spencer C.I., et al. (2012) In Vivo Reprogramming of Murine Cardiac Fibroblasts into Induced Cardiomyocytes. Nature, 485, 593-598.

[102] Song, K., Luo, X., Qi, X.Q., et al. (2012) Heart Repair by Reprogramming Non-Myocytes with Cardiac Transcription Factors. Nature, 485, 599-560.

[103] Kasahara, A., Cipolat, S., Chen, Y., Dorn II, G.W. and Scorrano, L. (2013) Mitochondrial Fusion Directs Cardiomyocyte Differentiation via Calcineurin and Notch Signaling. Science, 342, 734-737. http://dx.doi.org/10.1126/science.1241359

[104] Marlovits, S., Zeller, P., Singer, P., Resinger, C. and Vécsei, V. (2006) Cartilage Repair: Generations of Autologous Chondrocyte Transplantation. European Journal of Radiology, 57, 24-31. http://dx.doi.org/10.1016/j.ejrad.2005.08.009

[105] Johnson, K., Zhu, S., Tremblay, M.S., et al. (2012) A Stem Cell-Based Approach to Cartilage Repair. Science, 336, 717-721. http://dx.doi.org/10.1126/science.1215157

[106] Gauglitz, G.G. and Jeschke, M.G. (2011) Combined Gene and Stem Cell Therapy for Cutaneous Wound Healing. Molecular Pharmacology, 8, 1471-1479. http://dx.doi.org/10.1021/mp2001457

[107] Toyoshima, K., Asakawa, K., Ishibashi, N. et al. (2012) Fully Functional Hair Follicle Regeneration through the Rearrangement of Stem Cells and Their Niches. Nature Communications, 3, 784.

[108] Oshima, M., Mizuno, M., Imamura, A., Ogawa, M., et al. (2011) Functional Tooth Regeneration Using a Bioengineered Tooth Unit as a Mature Organ Replacement Regenerative Therapy. PLoS ONE, 6, e21531. http://dx.doi.org/10.1371/journal.pone.0021531

[109] Hanna, J., Saha, K. and Jaenisch, R. (2010) Pluripotency and Cellular Reprogramming: Facts, Hypotheses, Unresolved Issues. Cell, 143, 508-525. http://dx.doi.org/10.1016/j.cell.2010.10.008

[110] Rais, Y., Zviran, A., Geula, S., et al. (2013) Deterministic Direct Reprogramming of Somatic Cells to Pluripotency. Nature, 502, 65-70.

[111] Doulatov, S., Vo, L.T., Chou, S.S., et al. (2013) Induction of Multipotential Hematopoietic Progenitors from Human 
Pluripotent Stem Cells via Respecification of Lineage-Restricted Precursors. Cell Stem Cell, 13, 459-470. http://dx.doi.org/10.1016/j.stem.2013.09.002

[112] Hussein, S.M., Batada, N.N., Vuoristo, S., et al. (2011) Copy Number Variation and Selection during Reprogramming to Pluripotency. Nature, 471, 58-62.

[113] Tachibana, M., Amato, P., Sparman, M., et al. (2013) Human Embryonic Stem Cells Derived by Somatic Cell Nuclear Transfer. Cell, 153, 1228-1238. http://dx.doi.org/10.1016/j.cell.2013.05.006

[114] Liu, W., Li, M., Qu, J., Yi, F. and Liu, G.H. (2013) Reevaluation of the Safety of Induced Pluripotent Stem Cells: A Call from Somatic Mosaicism. Protein \& Cell, 4, 83-85. http://dx.doi.org/10.1007/s1323801229406

[115] Prandi, D. (1952) Bibliografia di Lazzaro Spallanzani. Sansoni Antiquariato, Firenze. 